\title{
SCROTAL ABDOMEN: A CASE REPORT
}

\section{Harindranath Harihara Ranganath ${ }^{1}$, Vinayak Chavan², Ravikar Jayraj3 ${ }^{3}$, Tejaswi Shashikant ${ }^{4}$}

\section{HOW TO CITE THIS ARTICLE:}

Harindranath Harihara Ranganath, Vinayak Chavan, Ravikar Jayraj, Tejaswi Shashikant. "Scrotal Abdomen: A Case Report". Journal of Evolution of Medical and Dental Sciences 2015; Vol. 4, Issue 23, March 19;

Page: 4062-4065, DOI: $10.14260 /$ jemds/2015/587

\begin{abstract}
Scrotal abdomen or Giant Inguino scrotal hernia, though an uncommon entity presents with operative dilemma as there are no standard surgical procedure. We present a case of giant inguinoscrotal hernia of a 49 yrs old male who had difficulty in performing his daily activities. Patient underwent mesh repair after reduction of content through inguinal and lower midline laprotomy with scotal reconstruction.
\end{abstract}

KEYWORDS: Giant inguino-scrotal hernia, mesh repair.

INTRODUCTION: Giant inginoscrotal hernia are defined as, extending beyond the midpoint of thigh in standing position. ${ }^{1}$ Such cases are due to neglect of symptoms by the patient till it affects the quality of life or present with complications. Operative intervention in such cases is associated with high mortality and post-operative complications. ${ }^{2}$ We present a case of giant inguinoscrotal hernia, irreducible with no co morbidities.

CASE REPORT: A 49yrs Auto rickshaw driver presented to us with the complains of swelling in right groin since 20yrs which was initially reducible and since last 5yrs its not reducible. Patient had difficulty in walking and performing his daily activities. Patient is a smoker since $30 \mathrm{yrs}$.

On examination: Right sided Ingunioscrotal swelling extending up to lower $1 / 3$ of thigh in standing position, non-reducible, cough impulse present, penis buried, right side testis was atropic. (Fig. 1).

Preoperatively patient was advised to quit smoking and incentive spirometry exercises for 2weeks.

Patient was operated under general anesthesia, after unsuccessful attempts of reduction of contents through right inguinal incision, a lower midline laparotomy incision was made and contents were reduced after Omentectomy. Closure was done with no undue tension. Excessive scrotal skin excised and scrotum reconstructed. (Fig. 3).

Contents of the sac included omentum, small bowel, appendix, ceacum and transverse colon. (Fig. 2).

Patient was extabutated after $24 \mathrm{hrs}$, monitored in intensive care for $48 \mathrm{hrs}$ and discharged on POD7 without any complications. Follow up at 1 month and 3 month except for pain at operated site at times, no other complains or complications noted. (Fig. 4). 


\section{CASE REPORT}

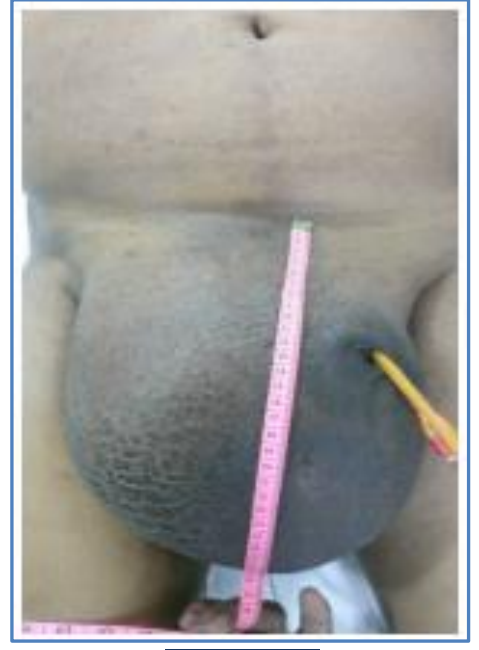

Fig. 1

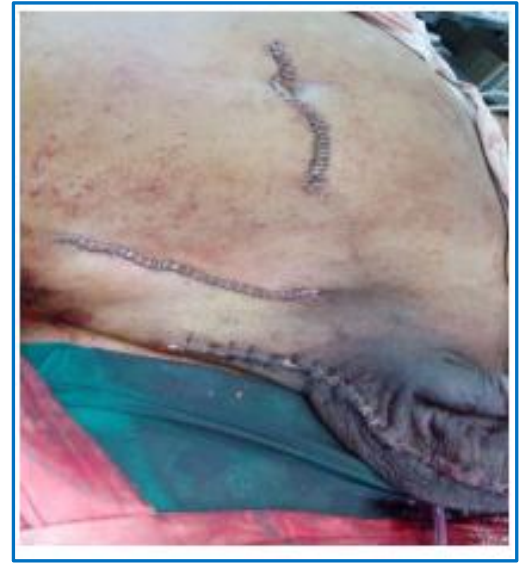

Fig. 3

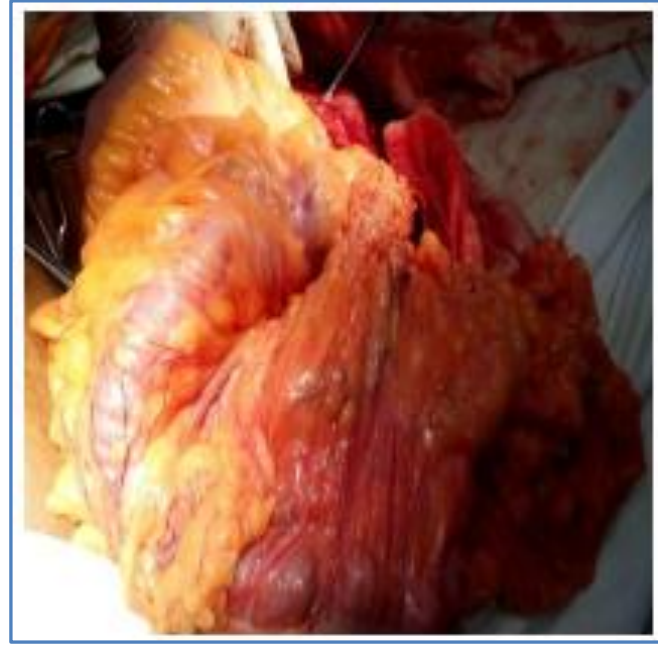

Fig. 2

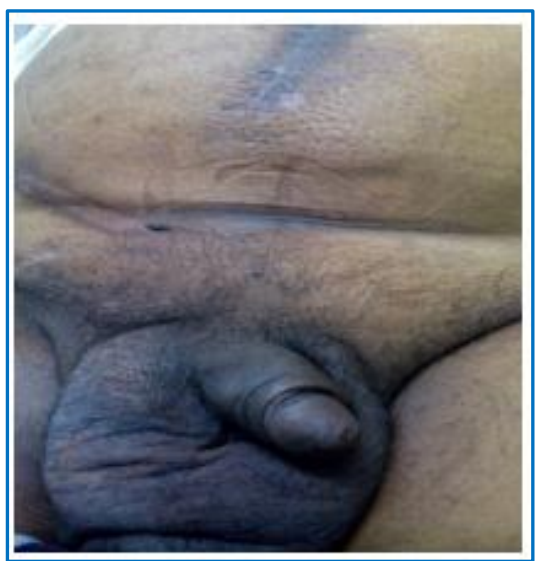

Fig. 4

DISCUSSION: Patient with giant inguinoscotal hernia present with difficutly in walking, sitting and lying down, difficulty in voiding due to buried penis, or complications like scrotal skin ulceration, intestinal obstruction and torsion of testis. ${ }^{3}$

Contents of hernia sac commonly include small bowel, omentum, appendix, ceacum and transverse colon, rarely include stomach, sigmoid colon, urinary bladder, kidney and ureter. ${ }^{4}$

In general the problems encountered during and post-surgery are:

1. Difficulty in reduction of contents.

2. Raised abdominal pressure leading to cardiorespiratory distress following reduction.

3. High recurrence rate due to large defect.

4. Excessive scrotal skin. ${ }^{5}$

Long standing giant inguinoscrotal hernia or scrotal abdomen causes decrease in abdomen capacity and adhesion between the contents and contents and sac which make the surgery 


\section{CASE REPORT}

complicated and reduction of contents produce respiratory compromise. The problem of reduction and post reduction complication can be minimized by either debulking of contents or increasing the abdominal capacity or creating midline defects.

Extensive bowel resections, for example total or hemicolectomy as well as omentectomy and even small bowel resections have been described. ${ }^{3}$ Progressive, artificially induced pneumoperitoneum has been attempted, but usually causes enlargement of the hernia sac, rather than the abdominal cavity and is therefore not very effective. Increasing the abdominal capacity by creating midline defects and closing it with component separation technique ${ }^{6}$ or inguinoscrotal flap as described by Merret et al, ${ }^{7}$ or tensor lata flap as reported by Mehendale et al. ${ }^{8}$

Preoperative chest physiotherapy and delayed extubation to overcome the respiratory distress which complicates the post-operative period due to rise of intra-abdominal pressure secondary to reduction. Bladder pressure monitoring to check for the rise in intraabdominal pressure during post-operative period. ${ }^{5}$

There is high chance of recurrence due to large defect which can be managed by mesh repair wherever possible. Excision of spermatic cord and testis has been practiced by some to avoid reconstruction of inguinal canal and potential chance for recurrence. ${ }^{9}$

Excessive scrotal skin can be excised if the patient prefers for cosmetic reasons or can be left behind to allow dartos to contract and retract over a period of time. Advantage of leaving behind scrotal skin that if patient develops respiratory complication in spite of above mentioned procedures then contents can be reduced back to scrotum. Scrotal drain to be placed insitu and firm compression bandageto prevent scrotal hematoma formation, drain can be removed on second post-operative day. ${ }^{7}$

CONCLUSION: Giant inguinoscotal hernia though uncommon surgical problem, management of which is challenging with fatal complications, can be dealt with adequate preoperative preparation, debulking of contents if necessary, mesh repair to prevent recurrence and postoperative monitoring to raised intrabdominal pressure and its complications.

\section{REFERENCES:}

1. Hodgkinson DJ, McIlrath DC. Scrotal reconstruction for giant inguinal hernias. Surg Clin North Am 1984; 64: 307-13.

2. Sarakbi W Al. Agarwal A. Taffinder N. A Giant inguinoscrotal hernia: a case report and review of literature. Grand rounds 2005; 5: 46-48.

3. Serpell JW, Polglase AL, Anstee EJ. Giant inguinal hernia. ANZ Journal of surgery. 1988; 58: 83134.

4. Tahir M, Ahmed FU, Seenu V. Giant inguinoscrotal hernia: case report and management principles. Int J Surg. 2008; 6: 495-7.

5. Coetzee, E., Price, C. \& Boutall, A. (2011). Simple Repair of a Giant Inguinoscrotal Hernia, International Journal of Surgery Case Reports 2011; 2(3): 32-5.

6. Ek, E. W., Ek, E. T., Bingham, R., Wilson, J., Mooney, B., Banting, S. W. et al. Component separation in the repair of a giant inguinoscrotal hernia. ANZ J Surg. 2006; 76: 950-952.

7. Merret ND, Water forth MW, Green MF. Repair of giant inguinoscrotal inguinal hernia using marlex mesh and scrotal skin flaps. Aust N J Z Surg 1994; 64: $380 \mathrm{e} 3$. 


\section{CASE REPORT}

8. Mehendale FV, Taams KO, Kingsnorth AM. Repair of giant inguinoscrotal hernia. Br J Plast Surg 2000; 53: 525e9.

9. King JN, Didlake RH, Gray RE. Giant inguinal hernia. South Med J 1986; 79: 252 e3.

\section{AUTHORS:}

1. Harindranath Harihara Ranganath

2. Vinayak Chavan

3. Ravikar Jayraj

4. Tejaswi Shashikant

\section{PARTICULARS OF CONTRIBUTORS:}

1. Associate Professor, Department of Surgery, Bangalore Medical College \& Research Institute, Bangalore.

2. Post Graduate, Department of Surgery, Bangalore Medical College \& Research Institute, Bangalore.

3. Assistant Professor, Department of Surgery, Bangalore Medical College \& Research Institute, Bangalore.

FINANCIAL OR OTHER COMPETING INTERESTS: None
4. Post Graduate, Department of Surgery, Bangalore Medical College \& Research Institute, Bangalore.

\section{NAME ADDRESS EMAIL ID OF THE CORRESPONDING AUTHOR:}

Dr. Harindranath Harihara Ranganath, House No. 1852,

First Cross, Prakash Nagar,

Bangalore-560021.

E-mail: harindranath82@gmail.com

Date of Submission: 20/02/2015.

Date of Peer Review: 21/02/2015.

Date of Acceptance: 07/03/2015.

Date of Publishing: 19/03/2015. 